\title{
Las imágenes de la nación, el arte como forma de representación social del Ecua- dor (1902-1941)
}

The nation images. The art as a social representation form of Ecuador (1902-1941)

\section{DAVID SÁNCHEZ DE ÁVILA}

Universidad de Cartagena

Colombia

*dsancheza203@gmail.com

(iD https://orcid.org/0000-0002-4148-9282

Artículo de investigación

Recepción: 24 de Septiembre de 2020

Aprobación: 03 de Noviembre de 2020

\section{Cómo citar este artículo:}

Sánchez de Ávila, D. (2021). Las imágenes de la nación, el arte como forma de representación social del Ecuador (1902-1941). Designio. Investigación en diseño gráfico y estudios de la imagen, 3(1), pp. 31-42. Recuperado a partir de: http://cipres. sanmateo.edu.co/index.php/designio

Reconocimiento-SinObraDerivada 4.0 Internacional (CC BY-NC-ND) 


\section{Resumen}

El presente artículo analiza la construcción de los sujetos sociales (actores sociales) que constituyen la nación, no en relación con los discursos hegemónicos de la historia tradicional o las narraciones con las cuales, en manos de diversos actores (blanco su mayoría), el Estado buscó resaltar el espíritu de la nación por medio de los lugares de la memoria y prácticas rituales. Más bien se enfoca en quiénes fueron los sujetos de inspiración de algunos artistas ecuatorianos en la primera mitad del siglo XX. Ellos construyeron un nuevo sentido sobre los sujetos de la nación, en particular para aquellos consumidores de arte pictórico a nivel nacional e internacional. Por lo tanto, el texto está enfocado en tres (3) artistas y tres (3) de sus obras: Joaquín Pinto con Orejas de palo (1902), Camilo Egas con Camino al mercado (1922-1923) y Eduardo Kingman con Los guandos (1941). Dichas obras son representativas del costumbrismo, el indigenismo y el realismo social (respectivamente).

Palabras clave: nación; arte; costumbrismo; realismo; representación; Ecuador.

\section{Abstract}

The present paper analyzes the construction of the social subjects - social actors- that constitute the nation, not regarding the hegemonic discourses of traditional history or the narratives with which in the hands of diverse actors (white-mestizos) the State seeks to highlight the spirit of the nation through the places of memory and ritual practices. Rather, it will focus on who were the subjects of inspiration for some ecuadorian artists in the first half of the 20th century, as these artists built a new sense of who were the subjects of the nation, particularly for those who consumed pictorial art nationally and internationally. It will therefore focus on three (3) artists and only three (3) of their works: Joaquín Pinto "Orejas de palo" (1902), Camilo Egas "Camino al mercado" (1922-1923) and Eduardo Kingman "Los guandos" (1941) representative works of costumbrismo, indigenismo and social realism (respectively).

Keywords: nation; art; manners; social realism; representation; Ecuador. 


\section{Introducción}

De acuerdo con los análisis realizados por diversos autores existe un consenso sobre cómo en un periodo de varias décadas el arte encontró cierta simbiosis con el interés de establecer las bases de la nación ecuatoriana en relación con sus características físicas del territorio. Lo anterior motivó el interés por la cartografía (Sevilla, 2013) y el arte paisajístico, claramente ejemplificado en el escudo nacional (Troya, 2015). Así, en los inicios del siglo XX el arte religioso y paisajístico en particular fueron dos (2) elementos en los cuales se cargó la simbología de la nación. Por esta razón las personas que habitaban estos espacios no eran más que sencillos elementos de contexto, medida, es decir, partes de una composición; no sus protagonistas, como sí lo serían el Chimborazo, el Pichincha o el río Guayas, por sólo mencionar algunos que estuvieron en el centro de la discusión como símbolos de la patria.

En este contexto, algunos autores de principio del siglo XX dieron un cambio de tuerca en relación con las obras de tipo religioso y paisajístico. Buscaron retratar de diversos modos a la población ecuatoriana desde diversos puntos de vista (folklorizada o explotada -subalternizada por decirlo de una forma más categórica-). En ese caso, este tipo de representación pictórica da un vuelco no sólo al interés artístico de los autores, también evidencia un cambio en los intereses de los consumidores de arte.

Ahora bien, el presente trabajo analiza tres (3) obras: Orejas de palo (1902) de Joaquín Pinto, 1902; Camino al mercado (1922-1923) de Camilo Egas y Los guandos (1941) de Eduardo Kingman; son representativas del costumbrismo, el indigenismo y el realismo social respectivamente. Así, se examinará la relación entre la representación de los sujetos en las obras y la composición de las mismas; tienen un correlato con las nuevas formas de representar a los sujetos que habitan la nación entre 1902-1941, razón por la cual se seguirá un orden cronológico de las obras analizar.

Las obras implícitamente se van alejando de los intereses propios del Estado, así como de ciertos sujetos de la sociedad quienes siguen interesados en apoyar y consumir otro tipo de arte vinculada con una figura más abstracta de la nación. De una u otra manera siguen desplazado a la población subalterna, en su mayoría indígena, negra y mestiza, como sujetos centrales en la construcción de los espacios que representan a la nación, sobre todo, se utilizan para construir los elementos que componen la nación imaginada o deseada. 
Por lo anterior, no es posible considerar que de manera consiente todos los artistas mencionados quisieran construir una nueva narrativa de la nación. Lo cierto es que al cambiar de foco el interés o protagonista de sus obras, sin duda se presenta la escenificación de un nuevo sentido sobre aquello que era importante expresar. Sobre un cambio en relación con quienes componen estos dispositivos, en otras palabras, aquellos que merecen ser pintados y en su conexión con las imágenes de una nación vista por medio de sus habitantes.

En el caso de Orejas de Palo (1902), Joaquín Pinto busca "tipificar" a los sujetos ubicados en los espacios públicos que transitan (o a los cuales pertenecen) debido a los trabajos o actividades que realizan. Este posicionamiento en el "mundo" establece a los protagonistas no solo en un punto geográfico, sino también en un punto del ecosistema social, es decir, permite entender las diferenciaciones sociales y jerarquías sociales (Pérez, 2010). La obra de Pinto hace referencia a un cargador de agua en particular (se dota al "tipo" de una personalidad especifica), una forma de reproducir y resignificar el costumbrismo.

Figura 1. Orejas de Palo

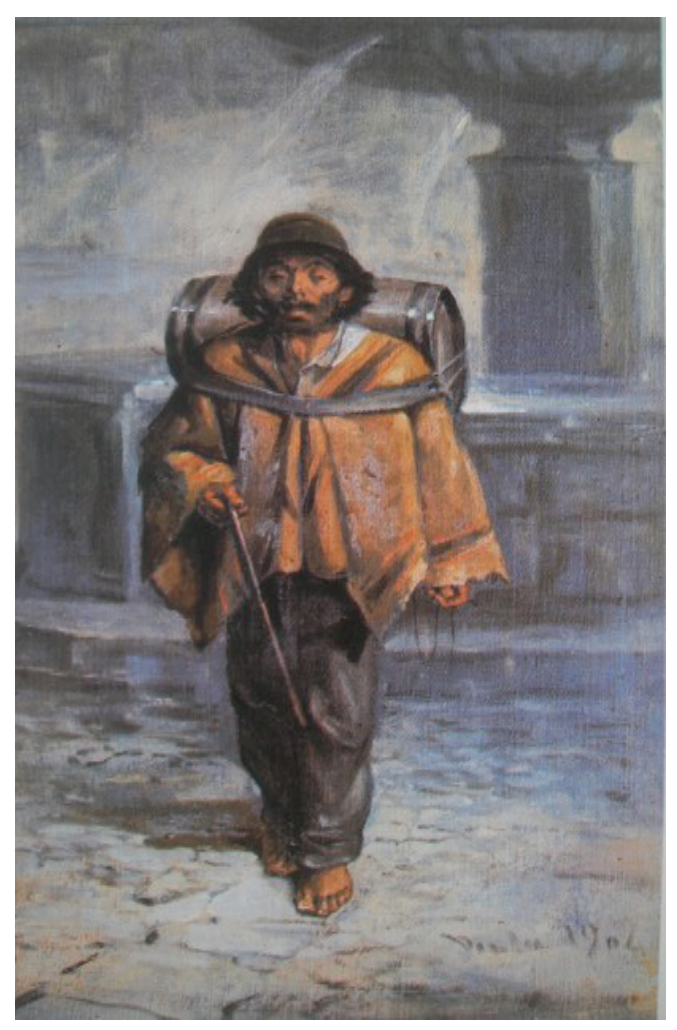

Fuente: Joaquín Pinto, Museo de Arte Colonial, 1902. 
jill Fitzell expresa que las imágenes adquieren sentido "cuando sus autores las utilizan para hacer un argumento dentro del [de un] discurso predeterminado" (Fitzell, 1994). Por ejemplo, en el caso de los relatos de viajeros parten del interés por conocer las condiciones sociales, económicas y naturales de las recién formadas repúblicas. Los relatos tienen un carácter expositivo de extranjeros para otros extranjeros (realizado por vanguardias capitalistas y las exploradoras sociales, científicos naturalistas, entre otros) (Pratt, 1997); en dicho periodo compartieron un "culto a lo exótico" (conocimiento empírico y subjetividad del deslumbramiento).

La producción cultural de la imagen (grabados, estampas, o ilustraciones) también debe ser analizada como una práctica de disciplinamiento en la construcción de los ciudadanos a finales del XIX y el XX' . Las imágenes dan cuenta de los imaginarios sobre la nación en el carácter (características) de los conciudadanos (buenas y malas costumbres, actitudes étnicas ante el trabajo).; las condiciones geográficas y climáticas (paisajismo); la fauna y flora que debía ser conquistada y explotada (naturalistas y vanguardistas capitalistas), entre otros aspectos que construyen una visión de la nación desde y hacia afuera y adentro.

Joaquín Pinto está relacionado con este tipo de relatos ya que la producción de dichas imágenes tenía el objetivo de ser consumidas por extranjeros; al llevarlas fuera del país reproducirían un "imaginario" o suerte de visión sobre la sociedad americana y ecuatoriana. Entonces, la construcción de los sujetos que realiza Pinto tiene una gran carga antropológica para el consumidor. El artista retrata a una persona por su importancia como sujeto tipológico de la nación, pero exótico para quien mire desde afuera. Por lo anterior, la importancia de las características de su ropa, el lugar en el espacio social, el trabajo que realiza y demás características únicas que forman una imagen de la población nacional.

El costumbrismo hace parte de una reproducción de los sujetos asociados a ciertas actividades (cargadores, aguatero, criados, vendedores de paja). Esto permitió desplazar la personalidad de los sujetos homogenizándolos dentro de una categoría relacionada con su trabajo. En este caso no se habla directamente sobre si el personaje de la obra es mestizo, negro o indígena; no quiere decir que dichas producciones no reproduzcan las ideas de segregación étnicas de la época, pues la

\footnotetext{
1 González Stephan ha analizado para el caso venezolano cómo el Manual de Carreño, la biografía y la fotografía respondieron a un proceso de disciplinamiento (formas de posar, de vestir), la imagen tiene un carácter político (Stephan, 2014). En ese mismo sentido el consumo de arte debe ser analizado tal como lo hace Bauer con el vestido. Funciona como forma de diferenciación para diversas clases las cuales desean establecer fronteras con otros grupos, al igual la imagen no solo representa de forma tipificada a los sujetos sociales, sino que el consumo de estas a petición demuestra un interés de ciertos sujetos de la elite y extranjeros por diferenciarse a través del retrato (Bauer, 2002).
} 
relación con el tipo de trabajo, en parte, corresponde a las ideas sobre las "razas". El vendedor de paja, La vendedora de leche o el Yndio de la capital de Agustín Guerrero da muestra de una condición étnica (el ser indígena). Sin embargo, lo que resalta su diferenciación es el tipo de trabajo, que define también una distancia social.

La relación que estos autores establecen con aquellos que reproducen o representan es impersonal; aluden a criterios de diferenciación que se cristaliza en su descontextualización y desarticulación del sufrimiento (por la explotación), reproduciendo el exotismo de las naciones latinoamericanas. Esta forma de representar también funcionó como una categoría de diferenciación y distanciamiento de las elites. Ellas quisieron reproducir la posición de inferioridad de forma inmediata y crear una mirada desde la extrañeza; en palabras de Trinidad Pérez: "'mantienen en su lugar' a aquellos que consideran distintos a ellas. Pero paradójicamente, como veremos más adelante, es a partir de esa distinción que se construye una imagen de nación" (Pérez, 2010, p. 158).

El indigenismo expresado por Camilo Egas en su obra Camino al mercado (1922-1923) debe ser considerada como una reproducción idealizada a nivel nacional; desde los trabajos académicos hasta los discursos políticos, pues en estos primeros años del siglo XX existió una necesidad de definir la imagen del indígena. Por ejemplo, en la fotografía de José Domingo Laso (2017) se ve el proceso de blanqueamiento étnico y social; su relato negaba la presencia de los indígenas en la ciudad, pues se buscaba construir una ciudad a la altura de las europeas (por medio de la reproducción mecánica de la fotografía). En ella el disciplinamiento (limpieza del cuerpo social) se consolida en la política evidente en la organización de la ciudad y el control policial sobre la vagancia², la prostitución (oficina de profilaxis) ${ }^{3}$, entre otros.

\footnotetext{
2 Ejemplo de esto es cómo los talleres artesanales se convierten en espacios de disciplinamiento por parte de los entes policiales, pero al mismo tiempo este proceso de aparente modernización llevó consigo la reproducción de ciertas prácticas pre modernas (como los sirvientes o las jerarquías de los implementada en los talleres). En palabras de Kingman (2008): "La organización artesanal era controlada por los maestros de los gremios con el apoyo de los organismos de policía. [...] Muchos niños eran entregados a los maestros para que aprendieran el oficio y se exigía lealtad en el cumplimiento de los compromisos de trabajo. [...] Los jóvenes de la ciudad que no participaban en un oficio podían ser encarcelados en casas correccionales o en un establecimiento de Artes y Oficios. Quienes no formaban parte de los gremios estaba en peligro de ser considerado vagos" (p. 247).

3 tascis expedidos por esta como dispositivos de control y vigilancia (2016).
} 
Figura 2. Camino al mercado

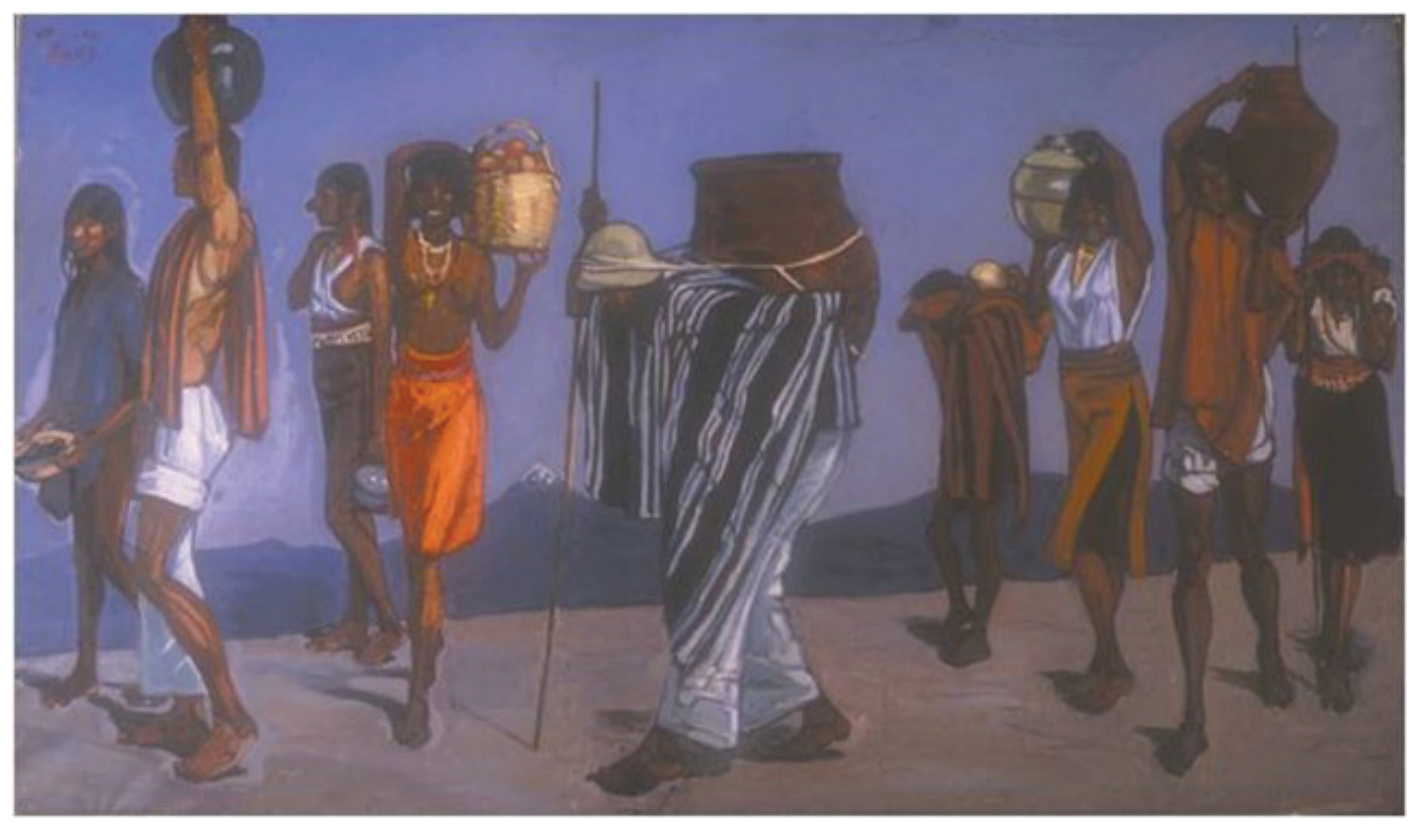

Fuente: Camilo Egas, Museo Camilo Egas, 1922-1923.

La reproducción de estas imágenes (mecánica o manual) hace parte del relacionamiento o la necesidad de imitar la concepción del espacio urbano europea en las ciudades americanas. Así, existió una necesidad por integrar las relaciones sociales y étnicas nacionales ante la identidad del otro, esto es, auto-representarse a partir de las formas visuales europeas (lo civilizado). Tal como lo hace Camilo Egas, la construcción del indígena se relaciona con un pasado, una construcción "positiva, si bien esencialista, del pasado precolombino" (Pérez, 2010, p. 161), inspirado en el origen mitológico (antigüedad clásica europea, según Pérez). Además, los elementos estéticos (cuerpos esbeltos, rostros risueños y el encuentro de miradas con el espectador) parten "del lenguaje del modernismo pictórico, un estilo afín al art-Nouveau, en vigencia en España desde fines del siglo XIX" (p. 163).

La imagen del indígena en la obra Camino al mercado (1922-1923) se analiza desde un distanciamiento, en parte, de Las floristas (1916) y El sanjuanito (1917). En estas dos (2) obras los sujetos representados están integrados como un conjunto, cuestión que cinco (5) y seis (6) años después se expresará en contraposición. En esta nueva composición los sujetos representados no están relacionados entre sí, además aluden a unos tipos definidos por sus diferentes actividades laborales (aunque todas estas se relacionan con "el cargar"). Se debe 
señalar que las continuidades de la obra son significativas, por ejemplo, la estilización de la imagen, los fondos que ubican al indígena en el espacio rural y la expresión de un pasado indígena (antes de la degeneración motivada por la colonización) continúan dándole un sentido a la imagen del cuerpo (estilizado) que se quería reproducir.

Por medio del "modernismo pictórico", y muy cerca de los indigenistas ecuatorianos contemporáneos y extemporáneos, Egas intentó construir a la población indígena a partir de "una imagen ideal que no proyecta conflictos ni disputas. Es la imagen del origen y la esencia misma de la nación moderna en construcción" (Pérez, 2010, p. 164). No se buscaba reproducir la imagen real del indígena, lo importante fue visibilizar y suplantar la imagen del indígena, limpia y moderna, basada en un pasado mítico, al tiempo relacionada con él y el mundo moderno.

Finalmente, por su parte el realismo social intentó representar la explotación de los cuerpos subalternos, incluso se podría decir, diferenciándose con el costumbrismo y el indigenismo. Alí los sujetos están extraídos de la explotación en la cual se encontraban, naturalizando su posicionamiento en la sociedad. Esto se muestra en la forma mítica de representación del indigenismo, de la extracción del contexto y la no expresión de sentimiento alguno de los "tipos".

Figura 3. Los guandos

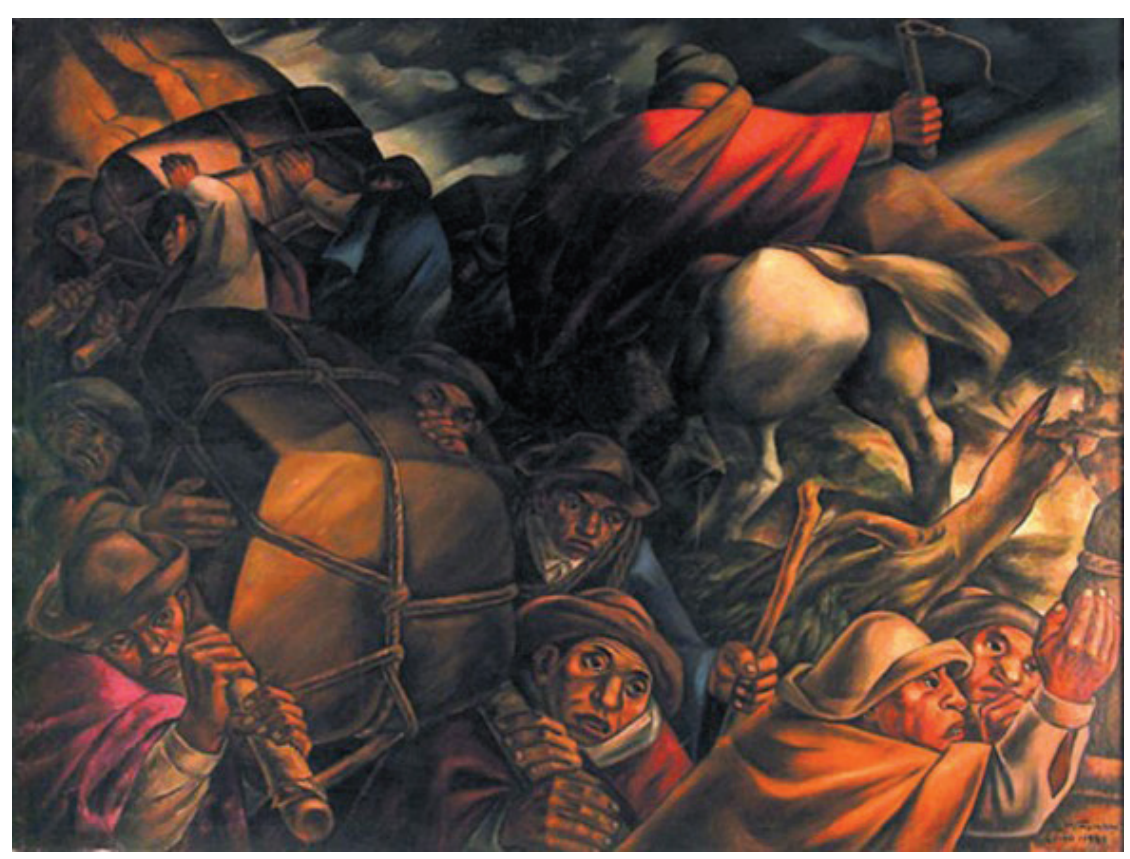

Fuente: Eduardo Kingman, Centro de Cultura Metropolitano, 1941. 
En relación con Eduardo Kingman Los guandos (1941) se debe resaltar su originalidad y diferenciación tanto del costumbrismo, indigenismo y muralismo. Dicha obra expresa un distanciamiento con las representaciones de tipos y costumbres; la ideología modernista que expresaba los prototipos por medios de representación pictóricas europeas; la representación de la clase trabajadora de forma homogénea (no se basaba en lo étnico); así como su efecto instigador en el espectador en el cual debía generar un deseo a pensar y actuar. Además, entre este autor y el muralismo mexicano existen ciertas distancias pues la crisis de la década de 1930 y la inestabilidad de los gobiernos en el Ecuador se expresó en la inconciencia de la función del arte como medio propagandístico y los recursos que permitieran promover el arte.

Si bien el uso de las manos agrandadas, los músculos marcados se ven también en la obra de Aguilera. El autor no tuvo acceso de forma directa a su obra; más allá de las reproducciones mecánicas a pequeña escala, el realismo de Kingman no expresa un difusionismo y apropiación de esos elementos, pues inicialmente la relación entre las obras, técnicas y conceptual fue mínima.

Los elementos pictóricos en las obras de Kingman dan cuenta del carácter de clase que quería expresar este realismo social. No se desea representar una imagen folclórica o tipificada del indígena relacionado con una identidad nacional, en cambio, se quiere evidenciar el trabajo en sus diferentes manifestaciones. Específicamente aquellas que dan cuenta del sufrimiento, esfuerzo y dolor dejado por la explotación que sufre la población trabajadora, tanto indígena de la región sierra, como la población mestiza-indígena de la región costa.

Ellos son retratados sufriendo las múltiples dimensiones de opresión de sus patronos, por ejemplo, la exhibición del castigo físico que vivía la población en las haciendas, la retención forzosa, las duras, largas y agonizantes jornadas de trabajo, entre otros sufrimientos expresados por el autor. Los guandos (1941) representaron una forma de subversión a los cánones de su periodo; por medio de la tradición virreinal religiosa se busca expresar el sufrimiento de los explotados, ello le permite crear un estilo propiamente ecuatoriano. Según las apreciaciones de Greet (siguiendo a Pérez), el autor remplaza la individualidad por el arquetipo del sufrimiento de la clase trabajadora.

A diferencia de Pinto quien en el costumbrismo también toma a sujetos específicos como Orejas de palo, quienes realizan un trabajo específico; el sentido o motivación de su representación cambia completamente. Por medio de los recursos 
artísticos no se muestra una idea de clase que homogenice la explotación de los cuerpos a partir de la demostración del dolor físico como se evidencia en el detaIle de los músculos (Trabajadores, 1934), la piel sucia por la actividad (El carbonero, 1934), el cansancio y tristeza (Saque de papas, 1939), propios del realismo social que dicho autor logró concretar en su obra Los guandos (1941). En ella dichos elementos se recogen y se perfeccionan con las técnicas del arte virreinal desarrolladas en la ciudad de Quito. En palabras de Greet (2007):

Kingman empleó las técnicas del arte colonial quiteño para transmitir el agudo sufrimiento de población indígena, así como para distinguir el Indigenismo ecuatoriano del mexicano y peruano, que no incorporaron las convenciones artísticas del arte virreinal. (p. 119)

A modo de conclusión debe señalarse que los tres (3) tipos de arte (costumbrismo, indigenismo y el realismo social) se distancian entre ellas a causa de los elementos artísticos que usan para representar la imagen de los sujetos integrados en la sociedad ecuatoriana (descontextualización, limpieza-estilización y exacerbación del sufrimiento por el sufrimiento). Además, los intereses de cada una de ellas se diferencian (distancia social y culto a lo exótico; integración del indígena [no degradado] al relato nacional gracias a su pasado mítico y la homogenización de la clase trabajadora, con el objetivo de generar conciencia social).

De igual manera es importante señalar que las tres (3) obras y los tres (3) artistas (así como otros muchos más, igual de importantes, pero por cuestión de tiempo no se abordaron) sin ninguna duda lograron modificar el ámbito de interés, o mejor dicho el sujeto de interés de las representaciones artísticas de este periodo. Cada uno logró posicionar a los sujetos sociales como elementos visibles de la nación, a su manera y con su propio interés. Sin embargo, también da cuenta de un periodo de transición social e intelectual de aquellos sujetos que están realizando el proceso de construcción de las diversas obras, es decir, nuevas posibilidades e intenciones individuales que se cuajan como un proceso de cambios en relación con el arte religioso y paisajístico.

La transición dejó un importante legado en relación con las representaciones de los sujetos que componen la nación, por lo tanto y en sí mismo, un proceso de construcción de los imaginarios de estas. En tal caso, el arte se convierte en un dispositivo al tiempo y espacio en donde se disputan los sentidos de la nación misma. 


\section{Referencias}

Bauer, A. (2002). Somos lo que compramos: Historia de la cultura material en América Latina. Ciudad de México: Taurus.

Checa Ron, S. (2016). Prostitución femenina en Quito: actores, perspectiva moral y enfoque médico (primera mitad del siglo XX). Procesos revista ecuatoriana de historia, N. ${ }^{\circ} 43,121-146$.

Fitzell, J. (1994). Teorizando la diferencia en los Andes del Ecuador: viajeros europeos, la ciencia del exotismo y las imágenes de indios. En B. Muratorio, Imágenes e imagineros: representaciones de indígenas ecuatorianos, siglos XIX y XX (págs. 47-73). Quito: FLACSO.

Greet, M. (2007). Pintar la nación indígena como una estrategia modernista en la obra de Eduardo Kingman. Procesos: Revista Ecuatoriana de Historia, 1(25), 93-119. https://doi.org/10.29078/rp.v1i25.193.

Kingman Garcés, E. (2008). La ciudad y los otros 1860-1940: Higienismo, ornato y policía. Quito: Flacso / Universitat Rovira i Virgili.

Laso, J. D. (2017). La huella invertida: antropologías del tiempo, la mirada y la memoria. La fotografía de José Domingo Laso 1870-1927. Montevideo: CDF.

Pérez, T. (2010). Las floristas y el Sanjuanito. En V. Coronel, Celebraciones centenarias y negociaciones por la nación ecuatoriana (págs. 23-75). Quito: 2010.

Pratt, M. L. (1997). Ojos Imperiales. Literatura de viajes y transculturación. Buenos Aires: Universidad Buenos Aires; Nacional de Quilmes.

Sevilla, A. (2013). El Ecuador en sus mapas: Estado y nación desde una perspectiva espacial. Quito-Ecuador: FLACSO.

Stephan, B. G. (2014). Las Tarjetas de visita: racialidad y disciplinamiento de ciudadanías blanqueadas en la pardocracia venezolana pos independentista. En S. Schuster, La nación expuesta: Cultura visual y procesos de formación de 
David Sánchez de Ávila

Troya, A. K. (2015). Elites y la Nación en Obras visuales y arquitectura del Ecuador 1840-1930. Cuenca: Universidad de Cuenca. 